\title{
African Nightshade and African Spinach Decrease Root-Knot Nematode and Potato Cyst Nematode Soil Infestation in Kenya
}

\author{
Oliver Chitambo, ${ }^{1}$ Solveig Haukeland, ${ }^{2}$ Komi K. M. Fiaboe, ${ }^{2}$ and Florian M. W. Grundler ${ }^{1, \dagger}$ \\ ${ }^{1}$ Rheinische Friedrich-Wilhelms-Universität Bonn, INRES Molecular Phytomedicine, D-53115 Bonn, Germany \\ ${ }^{2}$ International Centre of Insect Physiology and Ecology (ICIPE), P.O. Box 30772-00100, Nairobi, Kenya
}

\begin{abstract}
Plant-parasitic nematodes, particularly root-knot nematodes (RKN: Meloidogyne spp.) and cyst nematodes (CN: Globodera and Heterodera spp.) cause severe yield reduction in most cultivated crops and are of high economic importance. African nightshade (Solanum spp.) and African spinach (Amaranthus spp.) are important African indigenous vegetables (AIV) and are rich sources of nutrition and income. However, their host status to plant-parasitic nematodes remains largely speculative. Therefore, a survey was conducted which revealed that $S$. villosum exhibited high root galling, whereas on S. scabrum, A. cruentus, and A. dubius root galling was rare or very low. Additionally, soil collected from the rhizosphere of $S$. villosum and $S$. scabrum contained few cysts of potato cyst nematodes (PCN), and no developing PCN females were observed on the roots of growing plants. Therefore, we studied the dynamics of RKN and PCN on A. dubius, A. cruentus, S.

scabrum, and $S$. villosum over 2 years in a field experiment. The effects of AIV crop species on RKN and PCN soil infestation were evaluated using susceptible $S$. lycopersicum or $S$. tuberosum. After first, second, and third cultivation of A. dubius, A. cruentus, and S. scabrum, RKN infestation of the soil decreased by more than $85 \%$, whereas $S$. scabrum and S. villosum decreased PCN densities by more than $80 \%$. When cropping susceptible crops, after three seasons of successive cultivation of these AIV, galling index and number of developing PCN females measured on susceptible crops decreased by more than $75 \%$. Wilting and RKN-PCN coinfection incidences also decreased significantly. Here, we present data that support the development of a novel cropping system including African spinach and African nightshade, which reveals a high potential to manage RKN and PCN in an environmentally friendly, effective, and productive way.
\end{abstract}

Plant-parasitic nematodes, particularly tropical root-knot nematodes (RKN: Meloidogyne spp.) and cyst nematodes (CN: Globodera and Heterodera spp.) are plant pathogens of high economic importance causing severe yield losses in most cultivated crops. The life cycle of RKN and CN includes phases of survival in the soil, invasion of plant roots, and development inside root tissues. On susceptible host plants, rapid multiplication of nematodes inside root tissues leads to the development of disease symptoms such as root galling and cyst formation, respectively (Bartlem et al. 2013; Huang 1985; Perry 1989; Sijmons et al. 1991). This is associated with the formation of specific feeding cells from which they withdraw nutrients for the entire parasitic phase. As nematode-induced disease symptoms may impair water and nutrient uptake by the plant (Dropkin 1972; Jones 1981), yield losses of up to $30 \%$ have been reported on several crops such as potato, tomato, eggplant, and melon (Nicol et al. 2011). Yield loss caused by RKN and CN compromise the sustainability of crop production and is an obstacle for attaining food security.

${ }^{\dagger}$ Corresponding author: F. M. W. Grundler; grundler@uni-bonn.de

Current address of K. K. M. Fiaboe: IITA-Cameroun, BP. 2008 (Messa), Yaoundé, Cameroon

Funding: This work was conducted with funding from The Federal Ministry for Economic Cooperation and Development (BMZ) and Deutsche Gesellschaft für Internationale Zusammenarbeit (GIZ) GmbH, Project Number: 10270158 , and icipe core funding provided by UK Aid from the UK Government, Swedish International Development Cooperation Agency (Sida), the Swiss Agency for Development and Cooperation (SDC), and the Kenyan Government.

*The $\boldsymbol{e}$-Xtra logo stands for "electronic extra" and indicates that one supplementary figure is published online.

The author(s) declare no conflict of interest.

Accepted for publication 31 January 2019.

(c) 2019 The American Phytopathological Society
$\mathrm{RKN}$ and $\mathrm{CN}$ are obligate root parasites that have evolved highly sophisticated parasitic relationships with their host plants which are based on the formation of specific feeding sites (Hussey and Grundler 1998). The biology of RKN and $\mathrm{CN}$ is similar, consisting of developmental stages, egg, four juvenile stages, and the adult stage. However, potato cyst nematodes (PCN) tend to be much more host specific and require host stimulus for egg hatching (Perry and Clark 1977). The parasitic stage of RKN and PCN is entirely dependent on a suitable host plant and is highly vulnerable to the risk of starvation in the absence of a suitable host plant.

Numerous factors have contributed to the widespread occurrence of RKN and PCN in smallholder cropping systems. In Africa, these systems are complicated and often characterized by a simultaneous cultivation of crop species that supports development of RKN and PCN. This is aggravated by lack of awareness and proper nematode diagnostics. Thus, most farmers are unprepared and ill-equipped to respond effectively to the RKN and PCN problem. Consequently, RKN and PCN population densities have increased and their spread facilitated through the distribution of contaminated planting material, irrigation water, rainfall runoff, soil attached to farming implements, animal hooves, and footwear. In addition, intercontinental exchange of propagating material and trade has facilitated the global spread of highly damaging nematode species. This is well illustrated by the introduction of G. rostochiensis and G. pallida into Kenya (Mburu et al. 2018; Mwangi et al. 2015). Human-aided distribution of nematodes is further supported by the wide spread of RKN such as $M$. arenaria, $M$. incognita, and $M$. javanica in Africa and across the world (Onkendi et al. 2014; Wesemael et al. 2011). In addition, reports of some RKN species such as $M$. enterolobii are also on the rise (Chitambo et al. 2016; Coyne et al. 2018; Onkendi et al. 2014). The occurrence of PCN in smallholder farms is worrisome because RKN is already a heavy burden (Coyne et al. 2018). Accordingly, the presence of RKN and PCN threatens low-income farming systems which are essential for food production and livelihood.

Considering the above-mentioned situation, diminishing the yield loss caused by RKN and PCN is urgently required. The use of nematicides to control plant-parasitic nematodes has been gradually restricted due to undesirable effects on health and the environment 
(Zasada et al. 2010). Nevertheless, several techniques, such as soil tillage, plant-derived nematicidal compounds, sanitation, heatbased methods, biological control, green manure, trap crops, cover crops, and host resistance, are available to support the management of RKN and PCN (Bélair et al. 2016; Collange et al. 2011; Pickup 2016; Trudgill et al. 2014; Zasada et al. 2010). However, implementing these control methods alone is often not sufficient. RKN are capable of multiplying on resistant tomato and pepper varieties (Djian-Caporalino et al. 2011; Kiewnick et al. 2009), and certain populations of PCN are capable of multiplying on resistant potato varieties (Fournet et al. 2018). Recently, biological control products have been released to combat nematode problems, but their effects are not always reliable and consistent (Cray et al. 2016; Mwaura et al. 2017; Ward et al. 2012). Innovative strategies to control RKN and PCN are therefore urgently required.

In some African countries, there is renewed interest in African indigenous vegetables (AIV) because of their role in food and nutrition security. AIV such as African spinach (Amaranthaceae: Amaranthus spp.) and African nightshade (Solanaceae: Solanum spp.) are produced by farmers for food, nutrition, and livelihood security (Cernansky 2015; Dinssa et al. 2016; Gruber 2017; Moyo et al. 2017; Neugart et al. 2017; Ukam et al. 2016). The host status of African spinach and African nightshade to RKN and PCN varies in response to infestation by a range of species and environmental conditions. Several studies demonstrated that Amaranthus species such as A. cruentus are poor hosts for RKN (Ferris et al. 1993; Nchore et al. 2013; Rodríguez Kábana et al. 1988). A screening of non-tuber-bearing Solanaceous plants showed that $S$. nigrum species were resistant to PCN (Scholte 2000). Meanwhile, some studies indicate that species of African nightshade and African spinach might act as alternative hosts for RKN and PCN (Boydston et al. 2010; Kokalis-Burelle and Rosskopf 2012; Rott et al. 2011).
This created a conundrum regarding the precise host status of Amaranthus spp. and Solanum spp. to RKN and PCN, particularly under African conditions.

Here, we performed a field survey and detailed field trials to study the impact of nematodes on cultivation of AIV. The objectives of the current work were (1) to determine if Solanum spp. and Amaranthus spp. are hosts for RKN and PCN, (2) to determine the identity of RKN and PCN parasitizing Solanum spp. and Amaranthus spp., (3) to determine the population dynamics of RKN and PCN on Solanum spp. and Amaranthus spp., and (4) to determine the potential of Solanum spp. and Amaranthus spp. to manage RKN and PCN.

\section{Materials and Methods}

Plant-parasitic nematode survey of AIV in Kenya. African nightshade and African spinach are among the key AIV that have been targeted for promotion in Africa for smallholder farmer agroecosystems. We therefore conducted a survey during the period of June and August 2015 to study RKN and PCN root symptoms and soil infestation. Soil and root samples were collected from a total of 25 farms. At each farm, approximately 0.2 ha of land used for vegetable production was sampled. The following numbers of farms were visited in different counties: 4 in Kiambu County, 3 in Nyandarua County, 4 in Machakos County, 6 in Kakamega County, 5 in Murang'a County, and 3 in Busia County. The following crops were sampled: African nightshade (S. villosum and S. scabrum), African spinach (A. dubius and A. cruentus), potato (S. tuberosum), and tomato (S. lycopersicum). Root and soil samples collected from different counties were analyzed for occurrence of RKN and PCN. Crop damage levels were also determined.

RKN and PCN associated with each crop species were determined by uprooting the entire plants. Twelve plants were examined for each crop species at each farm. From this material, 12 samples of roots and

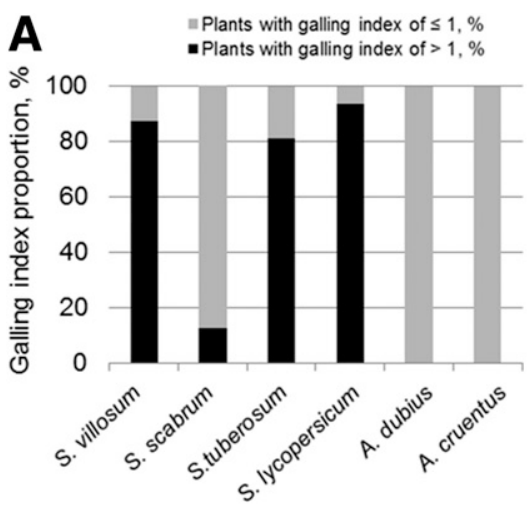

D

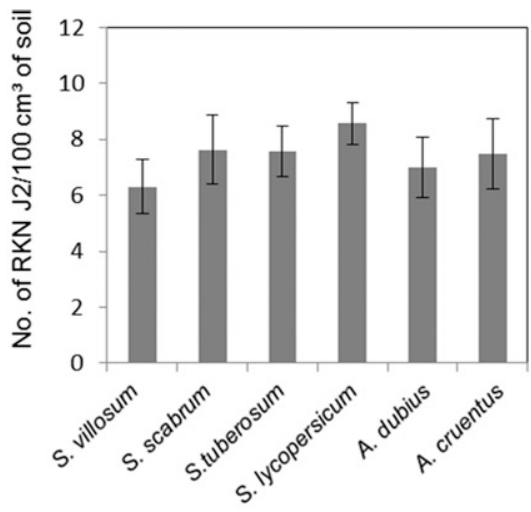

Crop species

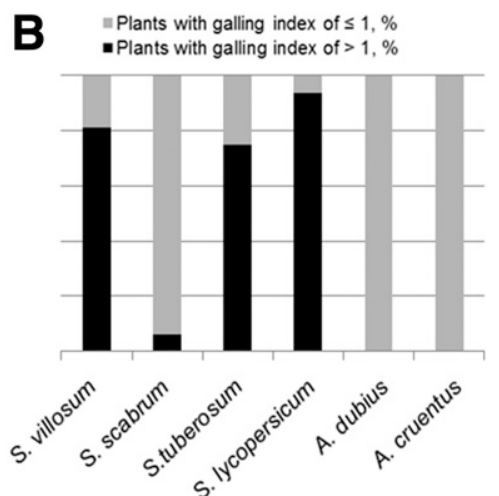

Crop species

$\mathbf{E}$

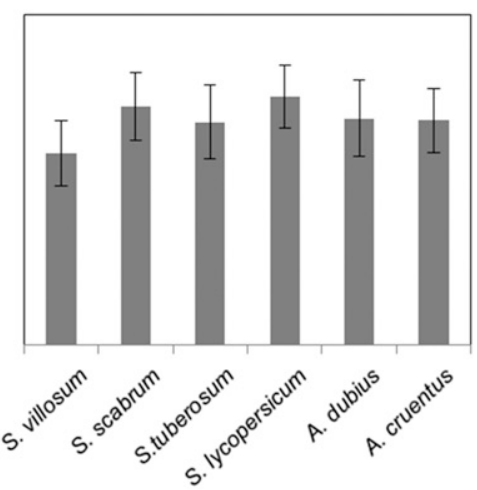

Crop species
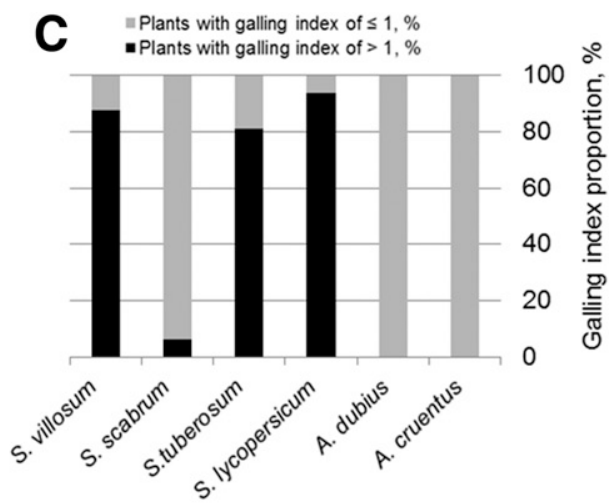

Crop species

$\mathbf{F}$

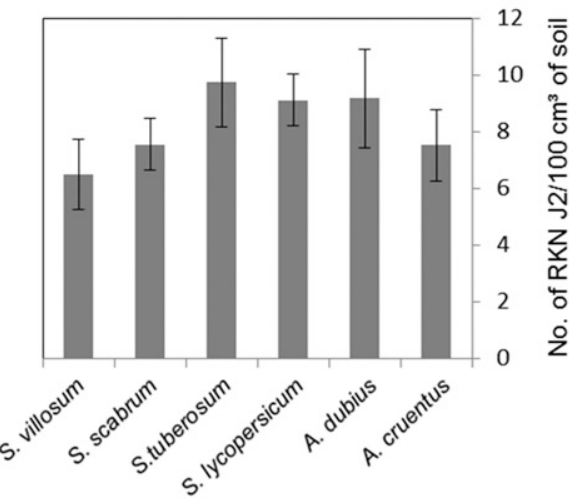

Crop species

Fig. 1. Root galling proportion: (A) Murang'a County, (B) Machakos County, and (C) Kakamega County. The corresponding root-knot nematode (RKN) soil infestation levels of second-stage infective juveniles (J2) isolated from rhizosphere of different crops: (D) Murang'a County, (E) Machakos County, and (F) Kakamega County. Values of the bars with different letters are significantly different at $P \leq 0.05$. A - Amaranthus, S - Solanum, RKN - root-knot nematodes, J2 - second-stage infective juveniles. 
adhering soil were collected at about a $15-\mathrm{cm}$ depth. RKN infestation was assessed as number of galls per plant and using a rating scale of 0 to 5 , where $0=$ no galls; $1=1$ to $2 ; 2=3$ to $10 ; 3=11$ to $30 ; 4=$ 31 to 100; and 5 = more than 100 galls (Taylor and Sasser 1978). PCN infestation was assessed by counting the number of females developed on the roots. Soil samples were mixed thoroughly and sieved before collecting five $100 \mathrm{~cm}^{3}$ subsamples for nematode extraction. RKN second-stage infective juveniles (J2) were extracted immediately, while for PCN, the soil was air-dried before cyst extraction. For RKN J2 extraction, a modified Baermann technique was used. RKN J2 were distinguished from other plant-parasitic nematodes by their typical morphology (Jepson 1987). RKN J2 were counted in $5 \mathrm{~cm}^{3}$ counting chambers under a 50× magnification stereo microscope (Leica MZ12, Nussloch, Germany). PCN were extracted using a Fenwick can. Briefly, individual subsamples of $100 \mathrm{~cm}^{3}$ of soil were rinsed, and cysts collected on the second sieve $(250 \mu \mathrm{m})$ were transferred to a filter paper. After drying, cysts were counted using a magnification lens. Ten cysts from different crop species were crushed separately in water, and three aliquots of each egg suspension were enumerated under a dissecting microscope at 25-50× magnification. Viability of eggs per cyst was assessed visually according to a standard protocol (Anonymous 2017).

Samples for RKN morphological analysis were analyzed within $72 \mathrm{~h}$ after collection. Identity of RKN females was assessed using perineal patterns (Eisenback et al. 1980). Perineal patterns were prepared from 20 females per county. For PCN cysts, cyst shape and color were used to discriminate PCN from other cyst nematodes. Mature females of RKN and PCN stored in absolute ethanol (99\%) were used for molecular analysis. In order to confirm the morphological results, NADH dehydrogenase subunit 5 (NAD5) and Cytochrome c oxidase I (COX1) were amplified and sequenced to determine species identity of RKN and PCN. Amplification and sequencing of RKN and PCN were carried out on 15 samples per crop. Briefly, genomic DNA was extracted from females. A single adult female nematode was immersed in $60 \mu \mathrm{l}$ of sterile water and was thoroughly crushed using a sterile toothpick. Thereafter, DNA was extracted using worm lysis buffer (WLB; $10 \mathrm{mM}$ Tris HCL, pH 8.0, $50 \mathrm{mM} \mathrm{KCl}$, $1.5 \mathrm{mM} \mathrm{MgCl}_{2}, 1 \mathrm{mM}$ DDT, $0.45 \%$ Tween 20 ) and proteinase $\mathrm{K}$. PCR amplification was carried out using Taq DNA polymerase (Qiagen, Germany), with $3 \mu$ l of extracted nematode genomic DNA and $0.5 \mathrm{mM}$ of each primer. Primers NAD5F2 (TATTTTTTGTTT GAGATATATTAG) and NAD5R1 (CGTGAATCTTGATTTTCCA TTTTT) were used to amplify the NAD5 gene (Janssen et al. 2016). COI gene was amplified using primers JB3 (TTTTTTGGGCAT CCTGAGGTTTAT) and JB4.5 (TAAAGAAAGAACATAATGAA AATG) (Derycke et al. 2010). The PCR amplification conditions were as follows: initial denaturation at $94^{\circ} \mathrm{C}$ for $2 \mathrm{~min}$, followed by 35 cycles of $94^{\circ} \mathrm{C}$ for $30 \mathrm{~s}, 55^{\circ} \mathrm{C}$ for $30 \mathrm{~s}$, and $72^{\circ} \mathrm{C}$ for $2 \mathrm{~min}$, with a final extension at $72^{\circ} \mathrm{C}$ for $7 \mathrm{~min}$. The PCR product was visualized on $1 \%$ gel stained with GelGreen (Biotium, U.S.A.). Each PCR amplicon was purified and subsequently submitted for direct Sanger sequencing (GATC Biotech, Germany).

Impact of AIV cultivation on population dynamics of RKN and PCN and subsequent nematode management in tomato and potato. The field trials were carried out at an experimental station at Kenya Agricultural \& Livestock Research Organization (KALRO $1.1518^{\circ} \mathrm{S} ; 36.6852^{\circ} \mathrm{E}$ ) from 2015 to 2017 . This site has a climate classified as warm and temperate. The climate at KALRO is considered to be $\mathrm{Cfb}$ according to the last revision of Köppen-
A $\quad$ Plants without developing PCN females, \% - Plants with developing PCN females, \%
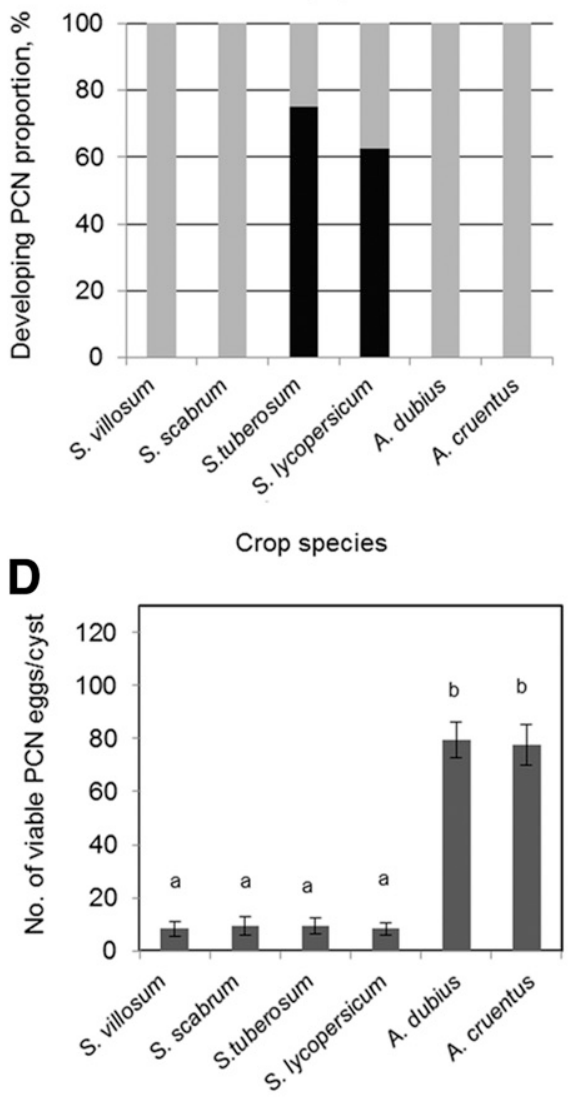

Crop species
B $\quad$ Plants without developing PCN females, $\%$
-Plants with developing PCN females, $\%$
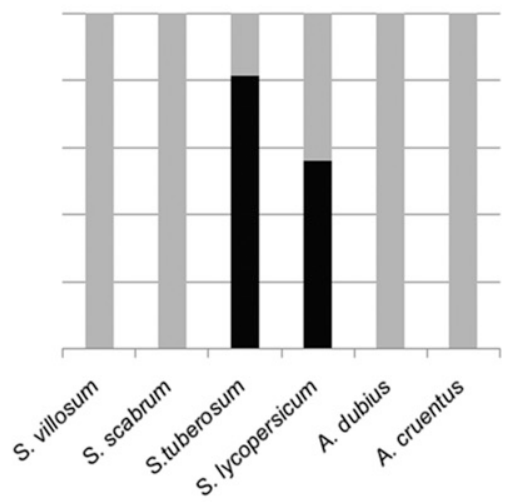

Crop species

E

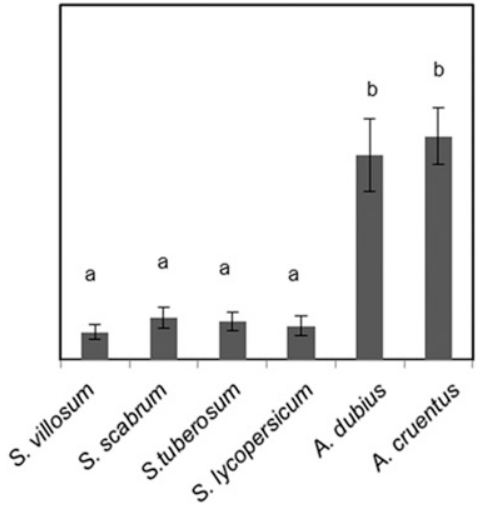

Crop species

\section{C $\|$ Plants without developing PCN females, $\%$ - Plants with developing PCN females, $\%$}
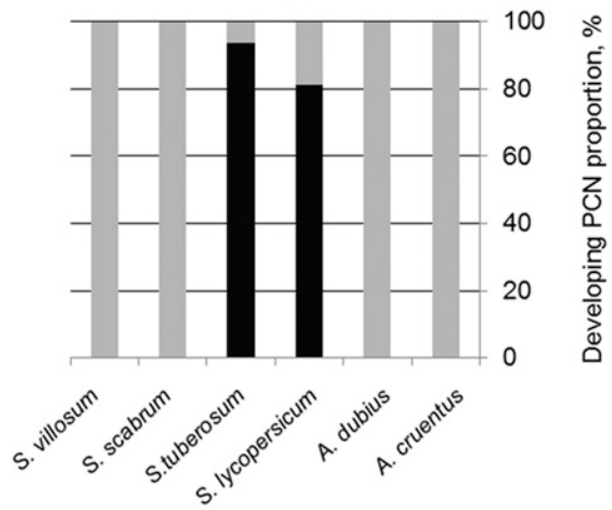

Crop species

$\mathbf{F}$

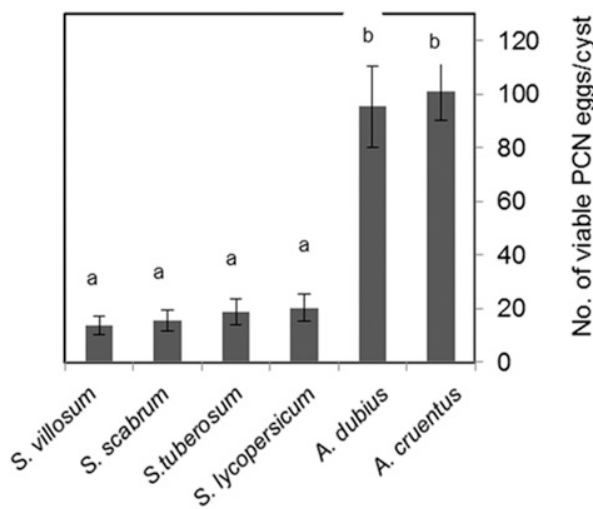

Crop species

Fig. 2. The proportion of plants with developing potato cyst nematodes (PCN) females: (A) Kiambu County, (B) Murang'a County, and (C) Nyandarua County. The corresponding PCN soil infestation levels isolated from rhizosphere of different crops: (D) Murang'a County, (E) Kiambu County, and (F) Nyandarua County. Values of the bars with different letters are significantly different at $P \leq 0.05$. A - Amaranthus, $\mathrm{S}$ - Solanum, $\mathrm{PCN}$ - potato cyst nematodes. 
Geiger climate classification (Kottek et al. 2006). The average temperature is $15.3^{\circ} \mathrm{C}$ and the average annual rainfall is $1,263 \mathrm{~mm}$. The sites had natural infestations of PCN and RKN. At the RKN site the following species were present: $M$. incognita, $M$. javanica, $M$. arenaria, M. enterolobii, and M. hapla as well as an associated Meloidogyne species. At the PCN site, G. rostochiensis and G. pallida were present, as well as an associated Globodera species. Both field trials had similar experimental parameters and were conducted across the following seasons: first growing season August to November 2015, second growing season February to May 2016, third growing season August to November 2016, and fourth growing season March to June 2017. Sampling was conducted at preplanting, 6 weeks after planting, and 12 weeks after planting.

The experiment was a randomized complete block design with main plots measuring $10 \times 10 \mathrm{~m}$. The main plots were subdivided into subplots of $3 \times 3 \mathrm{~m}$. The plots were maintained and used in each growing season. AIV and tomato seeds were sourced from Simlaw Seeds Company Ltd. (Nairobi, Kenya). Seed potatoes were sourced from the seed production unit of KALRO (Tigoni, Kenya). AIV and tomato seeds were sown and raised in a nursery bed for 1 month before being transplanted in the field at a planting density of 14 plants $/ \mathrm{m}^{2}$. Chitted potato tubers were planted at 10 plants $/ \mathrm{m}^{2}$. Well-decomposed cow manure was incorporated at a rate of 4 $\mathrm{kg} / \mathrm{m}^{2}$ before planting. The seedlings were irrigated after transplanting to enhance their establishment. Thereafter, the crop was managed in accordance to the normal farmer's practices. During the dry spell, supplemental irrigation was applied.

The experiment consisted of two phases. In the first phase, the impact of AIV on the population dynamics of RKN and PCN was considered. African nightshade (S. scabrum and S. villosum) and African spinach (A. dubius and A. cruentus) were selected for inclusion in the experiment because of their widespread cultivation in the region. The crops were grown for three successive seasons in main plots (i.e., first, second, and third growing seasons). In the second phase of the experiment, the effect of cultivating AIV for three successive seasons on RKN and PCN management was assessed by the cultivation of susceptible crops ( $S$. lycopersicum cv. Moneymaker and $S$. tuberosum cv. Shangi) in the fourth growing season. The following cropping sequences were adopted to assess effects of AIV cropping system on RKN: (1) 3 seasons A. dubius-followed by-S. lycopersicum, (2) 3 seasons $S$. villosum-followed by-S. lycopersicum, and (3) 3 seasons $S$. scabrum-followed by-S. lycopersicum. The following cropping sequences were adopted to assess the effects of AIV cropping system on PCN: (1) 3 seasons fallow-followed by-S. tuberosum, (2) 3 seasons A. dubius-followed by-S. tuberosum, (3) 3 seasons $S$. villosum-followed by-S. tuberosum, and (4) 3 seasons $S$. scabrum-followed by-S. tuberosum. Plots that were previously under A. cruentus were not included in the second phase. Collection of data on $\mathrm{J} 2$ soil population density, galling index, and number of viable cysts was determined as described above. Visual assessment
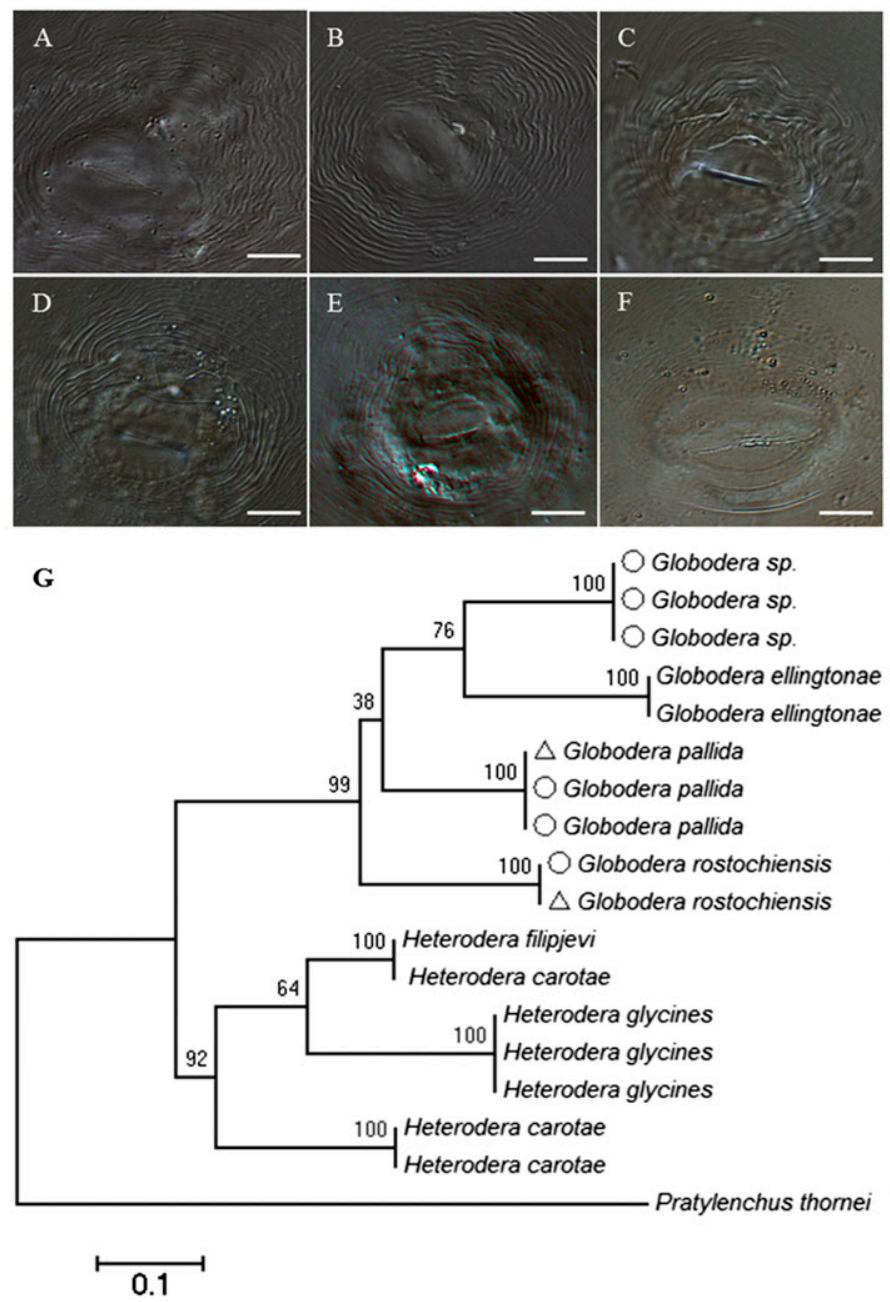

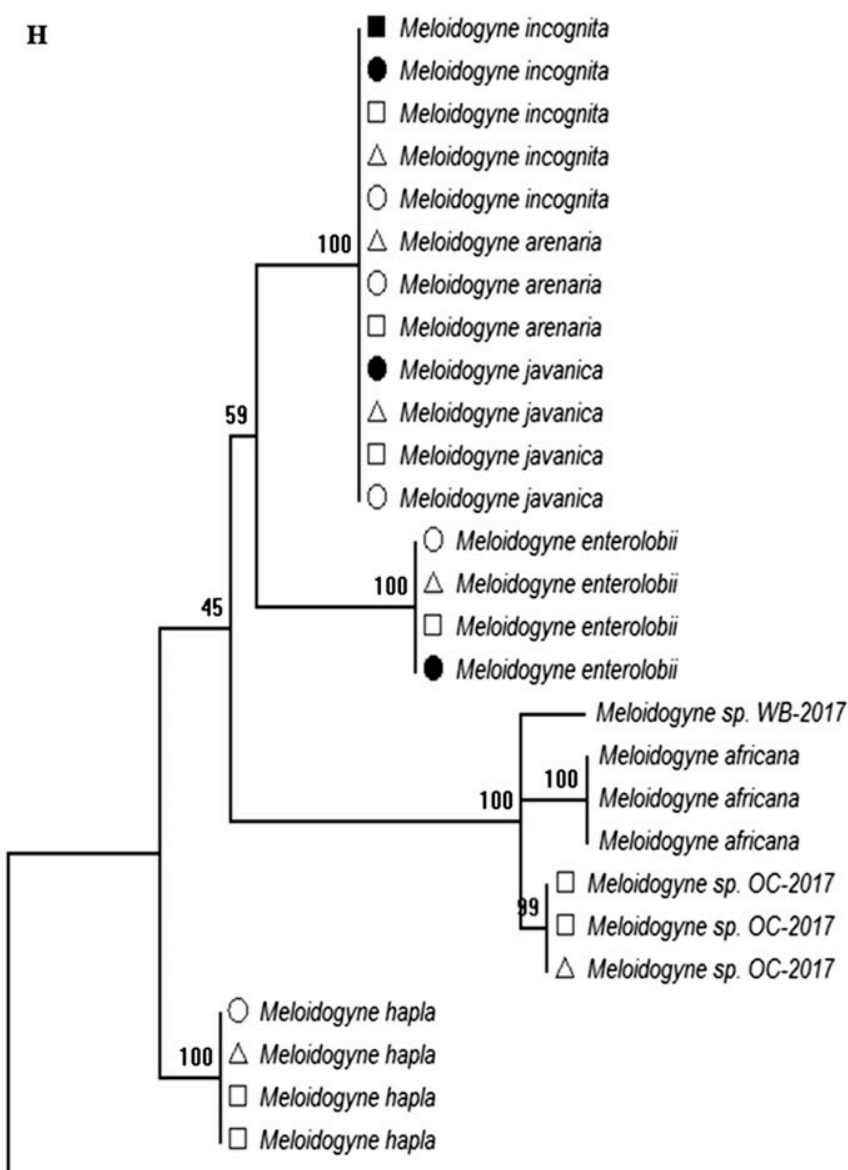

Pratylenchus thomei

Fig. 3. Determination of root-knot nematodes (RKN) and potato cyst nematode (PCN). (A-F) Perineal pattern of RKN isolated from different crop species: (A-C) Meloidogyne incognita, M. javanica, and M. arenaria, (D) M. hapla, (E) M. enterolobii, and (F) Meloidogyne sp. (G) Phylogenetic tree based on mitochondrial cytochrome oxidase I (COI) sequences of Globodera and Heterodera spp. (H) Phylogenetic tree based on mitochondrial COI sequences of RKN. Values above branches are Maximum Likelihood bootstrap values. For details on phylogenetic reconstruction see Materials and Methods. The following symbols represent the host plant from which the adult nematodes were extracted: $\bigcirc$ S. tuberosum, $\square$ S. villosum, $\square$. dubius, $\bigcirc$. scabrum, and $\Delta$ S. lycopersicum. A - Amaranthus, S - Solanum. Scale bar $=25 \mu \mathrm{m}$. 
on plant health was also performed and recorded as slightly wilted, wilted, severely wilted, or nearly dead. To confirm the presence of bacterial wilt (Ralstonia solanacearum) on the wilted plants, the crown was cut and placed in water. Bacteria oozed from the exposed vascular elements of wilted plants in 8-12 min, forming milky strands flowing into water and confirming the presence of $R$. solanacearum (Riley et al. 2002). The presence of galls and developing PCN females on the same plant was used to assess RKN-PCN coinfection. Plants were considered coinfected if RKN and PCN females were observed on the roots of the same plant. The number of flowers per plant as a measure for productivity was counted from the same treatments after assessing wilting and coinfection incidences.

Data and statistical analysis. During the survey, RKN crop damage was categorized as the proportion of plants with a galling index $\leq 1$ and $>1$. For PCN, crop damage was expressed as the proportion of plants with developing PCN females and those without. RKN and PCN crop damage was then expressed as a percentage of the total number of plants sampled per individual crop species. Visited farms were analyzed at the county level.

In the controlled experiment, wilting incidences were calculated for each treatment as the proportion of wilted plants expressed as a percentage of total number of plants sampled. RKN-PCN coinfection incidence was calculated as the proportion of plant roots simultaneously infected by both RKN and PCN expressed as a percentage of a total number of plants sampled. Nematode density data were $\log _{10}(x+1)$ transformed before analysis in order to meet normality and constant variance assumptions. Repeated measures analysis of variance was used to test the effect of AIV on abundance of J2 of RKN and PCN viable eggs and galling index. Analyses of variance (ANOVA) were conducted to assess the impact of AIV on developing PCN female nematodes, wilting incidences, RKN galling index, and number of flowers on subsequent susceptible crop. A $P$ value $\leq 0.05$ was considered statistically significant. All statistical analyses were performed using SigmaPlot v. 12.5 (Systat Software, San Jose, CA, U.S.A.).

Nematode DNA sequences were first queried via Standard Nucleotide BLAST search (https://blast.ncbi.nlm.nih.gov/Blast.cgi) in order to examine whether the sequence would match any species in the database (Altschul et al. 1990). ClustalW (https://www.ebi.ac.uk/ Tools $/ \mathrm{msa} /$ clustalo/) was used for a detailed comparison of obtained DNA sequences with related reference sequences of related species. Phylogenetic analyses were conducted using MEGA version 6, and maximum likelihood analyses were conducted with 5,000 bootstrap replicates under the GTR + I + G model according to Tamura et al. (2013).

\section{Results}

Plant-parasitic nematode survey of AIV in Kenya. Consistently, S. lycopersicum, $S$. villosum, and $S$. tuberosum plants had galling indices of $>1$, whereas $A$. dubius, A. cruentus, and $S$. scabrum plants were associated with galling indices of $\leq 1$ across the counties studied (Fig. 1A-C). A further examination of the soil showed no statistical differences in RKN J2 population densities (Fig. 1D-F). There was a low number of RKN J2 in soil extracted from the root rhizosphere of A. dubius, A. cruentus, and S. scabrum despite consistent galling indices of $\leq 1$ across the counties. Similarly across the counties, $S$. tuberosum and $S$. lycopersicum were associated with developing PCN females on their roots. In contrast, no developing PCN females were recorded on A. dubius, A. cruentus, S. scabrum, and $S$. villosum (Fig. 2A-C). There was no statistical difference in the number of viable PCN eggs/cyst collected from S. tuberosum, S. lycopersicum, S. scabrum, and S. villosum (Fig. 2D-F). Although no developing PCN females were observed on A. dubius and A. cruentus, the number of viable PCN eggs/cyst extracted was high.

Some RKN species could be clearly identified based on female perineal pattern, but morphological differentiation was not possible between $M$. javanica, $M$. arenaria, and $M$. incognita. RKN female perineal patterns from pure cultured samples ranged from the general lateral ridges that divide the dorsal and ventral striae observed on $M$. javanica to high, squarish dorsal arch that is normally observed on M. incognita (Fig. 3A-C). M. hapla female patterns were characterized by flattened ovoidal shape and subcuticular punctations in the smooth tail terminal area, and the lateral ridges were absent (Fig. 3D). Female perineal patterns of $M$. enterolobii were round to dorso-ventrally ovoid. Lateral lines were not distinguishable

Table 1. Root-knot nematode (RKN) and potato cyst nematode (PCN) species identified from different crops in five counties in Kenya using mtDNA-based technique

\begin{tabular}{|c|c|c|c|c|c|c|c|}
\hline \multirow{3}{*}{$\begin{array}{l}\text { Crop species } \\
\text { County }\end{array}$} & \multicolumn{2}{|c|}{ African spinach } & \multirow{2}{*}{ 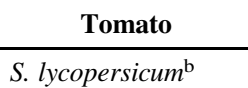 } & \multirow{2}{*}{$\begin{array}{r}\text { Potato } \\
\text { S. tuberosum } \\
\text { c }\end{array}$} & \multicolumn{2}{|c|}{ African nightshade } & \multirow[t]{3}{*}{ Sequences (NAD5/COI) ${ }^{\mathrm{a}}$} \\
\hline & A. dubius & A. cruentus & & & S. scabrum & S. villosum ${ }^{\mathrm{b}}$ & \\
\hline & \multirow{2}{*}{\multicolumn{6}{|c|}{ Nematode species ${ }^{\mathrm{d}}$}} & \\
\hline & & & & & & & Accession numbers \\
\hline Kakamega & $x$ & $x$ & $\mathrm{Ma}, \mathrm{Mi}$, and $\mathrm{Mj}$ & - & $x$ & $\mathrm{Ma}, \mathrm{Mi}$, and $\mathrm{Mj}$ & $\begin{array}{c}\text { MH399836, MH399835, } \\
\text { MH399834, MH399833, } \\
\text { MH399843, MH399842, } \\
\text { MH399841, MH399825 }\end{array}$ \\
\hline Kiambu & $\mathrm{Mi}$ & $\mathrm{Mi}$ & $\begin{array}{l}\text { Ma, Me, Mh, Mi, } \\
\text { Mj, Msp., and Gr }\end{array}$ & $\begin{array}{l}\text { Ma, Me, Mh, Mi, } \\
\text { Mj, Gr, Gp, and Gsp. }\end{array}$ & $\mathrm{Me}$ and $\mathrm{Mj}$ & $\begin{array}{l}\text { Ma, Me, Mh, Mi, } \\
\text { Mj, and Msp. }\end{array}$ & $\begin{array}{c}\text { MH005023, MH005027, } \\
\text { MH005026, MH005025, } \\
\text { MH399805, MH399832, } \\
\text { MH399802, MH399817, } \\
\text { MH399820, MH399823, } \\
\text { MH399822, MF322782 }\end{array}$ \\
\hline Machakos & $x$ & $x$ & $\mathbf{M a}, \mathrm{Me}, \mathbf{M i}$, and $\mathrm{Mj}$ & - & $\mathrm{Me}$ and $\mathrm{Mi}$ & $\begin{array}{l}\mathrm{Ma}, \mathbf{M e}, \mathbf{M i}, \\
\text { and } \mathbf{M j}\end{array}$ & $\begin{array}{l}\text { MH399837, MH399845, } \\
\text { MH399844, MH399824 }\end{array}$ \\
\hline Murang'a & $x$ & $\mathrm{Mi}$ & $\begin{array}{l}\mathrm{Ma}, \mathrm{Me}, \mathrm{Mh}, \mathrm{Mi} \text {, } \\
\mathrm{Mj} \text {, and } \mathrm{Gr}\end{array}$ & $\begin{array}{l}\mathrm{Ma}, \mathrm{Me}, \mathbf{M h}, \mathbf{M i} \text {, } \\
\text { Mj, and } \mathrm{Gr}\end{array}$ & $\mathrm{Mj}$ & $\begin{array}{l}\mathrm{Ma}, \mathbf{M e}, \mathrm{Mh}, \mathbf{M i} \text {, } \\
\text { and } \mathrm{Mj}\end{array}$ & $\begin{array}{l}\text { MH399832, MH399831, } \\
\text { MH399829, MH399828, } \\
\text { MH399839, MH399838, } \\
\text { MH399803, MH399801, } \\
\text { MH399816, MF773722 }\end{array}$ \\
\hline Nyandarua & $x$ & $x$ & $\begin{array}{l}\text { Ma, Mh, Mi, Mj, } \\
\text { and } \mathrm{Gr}\end{array}$ & $\begin{array}{l}\text { Ma, Mh, Mi, Mj, } \\
\text { Gr, and Gp }\end{array}$ & $x$ & $\begin{array}{l}\mathrm{Ma}, \mathrm{Mh}, \mathrm{Mi} \text {, } \\
\text { and } \mathrm{Mj}\end{array}$ & $\begin{array}{c}\text { MH399827, MH005024, } \\
\text { MH399830, MH399800, } \\
\text { MH399815, MH399818 }\end{array}$ \\
\hline
\end{tabular}

\footnotetext{
a NAD5 = NADH dehydrogenase subunit 5 . COI = Cytochrome $\mathrm{c}$ oxidase I.

${ }^{\mathrm{b}} \mathrm{RKN}$ multiple species infection were detected.

${ }^{\mathrm{c}} \mathrm{RKN}-\mathrm{PCN}$ coinfection were detected.

${ }^{\mathrm{d}} \mathrm{Ma}=$ Meloidogyne arenaria, $\mathrm{Me}=$ M. enterolobii, $\mathrm{Mh}=$ M. hapla, $\mathrm{Mi}=$ M. incognita, $\mathrm{Mj}=$ M. javanica, $\mathrm{Msp} .=$ Meloidogyne $\mathrm{sp} ., \mathrm{Gr}=$ Globodera rostochiensis, $\mathrm{Gp}=$ G. pallida, $\mathrm{Gsp} .=$ Globodera sp. Species in bold were detected in combination from a single plant. $\mathrm{x}=$ no RKN or PCN were detected from the roots. $-=$ no crop was observed.
} 
(Fig. 3E). Some of the perineal patterns of a sample of RKN females from $S$. villosum and $S$. lycopersicum did not conform to the normal description of other RKN. These perineal patterns were characterized by very fine striae and very low dorsal arch (Fig. 3F); it could not be assigned to a described species. The spherical brown cysts isolated from the soil and pale yellow females observed on the roots were identified as $G$. rostochiensis or G. pallida. In some samples, cysts were light brown to brown in color and subspherical, which did not conform to the normal description of G. rostochiensis or G. pallida, indicating the occurrence of an associated Globodera $\mathrm{sp}$.

DNA sequence blasting and sequence alignment of COI gene identified the following RKN species (Table 1; Fig. 3H); M. hapla parasitizing $S$. lycopersicum, $S$. tuberosum, $S$. villosum, and $S$. scabrum (accession numbers KX137039, MH399800-MH399802), M. enterolobii parasitizing S. lycopersicum, S. tuberosum, S. villosum, and S. scabrum (accession numbers KT936633, MH399803-MH399805), and an associated Meloidogyne sp. parasitizing S. lycopersicum and S. villosum (accession number MF351699). This region failed to differentiate $M$. javanica, $M$. incognita, and $M$. arenaria. Therefore, DNA sequence blasting and sequence alignment of NAD5 gene was used to differentiate these species. The sequence alignment of the NAD5 gene identified $M$. javanica parasitizing $S$. lycopersicum, S. tuberosum, S. villosum, and S. scabrum (accession numbers KY436071, MH399831-MH399837), M. arenaria parasitizing $S$. lycopersicum, S. tuberosum, S. villosum, and S. scabrum (accession numbers MH399824-MH399830), and M. incognita parasitizing $S$. lycopersicum, S. tuberosum, S. villosum, S. scabrum, A. dubius, and A. cruentus (accession numbers MH005027, MH399838-MH399845). Phylogenetic analysis based on the COI gene sequence revealed an associated Meloidogyne sp. closely related to M. africana (Fig. 3H).
Three PCN species were identified based on COI DNA analysis (Table 1; Fig. 3G): G. rostochiensis (accession numbers MF773722, MH399815-MH399817), G. pallida (accession numbers MH399818MH399820), and an associated Globodera sp. (accession numbers MG438286, MH399821-MH399823), which is closely related to G. ellingtonae.

Impact of AIV cultivation on population dynamics of RKN and PCN and subsequent nematode management in tomato and potato. Our survey results showed that RKN parasitism was very low on $A$. dubius, $A$. cruentus, and $S$. scabrum. A field trial was conducted at a site that had natural soil infestation of $M$. incognita, $M$. javanica, $M$. hapla, $M$. enterolobii, and an associated Meloidogyne sp. At the beginning of the experiment, no significant differences in RKN population densities existed among the plots assigned to different crop treatments (Fig. 4A). By the end of the first season, population densities of RKN were significantly increased under $S$. villosum and were significantly reduced under A. dubius, A. cruentus, and S. scabrum (Fig. 4A). In seasons 2 and 3, these dynamics continued. However, the successive cultivation of susceptible $S$. villosum promoted RKN soil infestation and root galling (Fig. 4A and B) and severe wilting and root galling (Supplementary Fig. S1D and E). The two species of African spinach achieved a similar RKN suppressive effect. Therefore, plots under A. cruentus were not considered in the next experiment. After three successive seasons of cultivating AIV, a RKN-susceptible S. lycopersicum cv. Moneymaker planted under AIV resulted in different galling indices and number of flowers at 6 weeks after planting. The galling indices were lower in S. scabrum and A. dubius, and the number of flowers were higher compared with S. villosum (Fig. 4C).

In our survey, no adult PCN females were observed on $S$. scabrum and $S$. villosum, and very few viable PCN eggs were found in cysts extracted from the soil surrounding the roots of these plants. A field
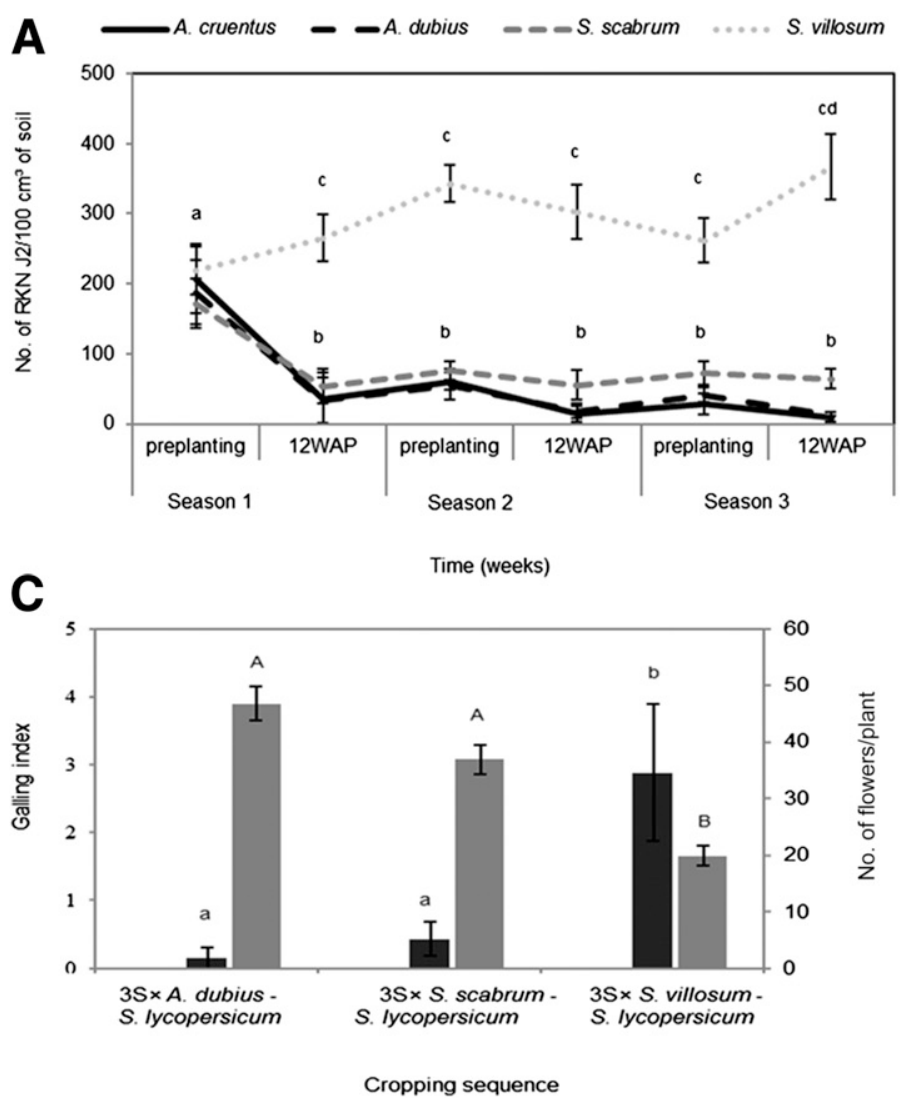
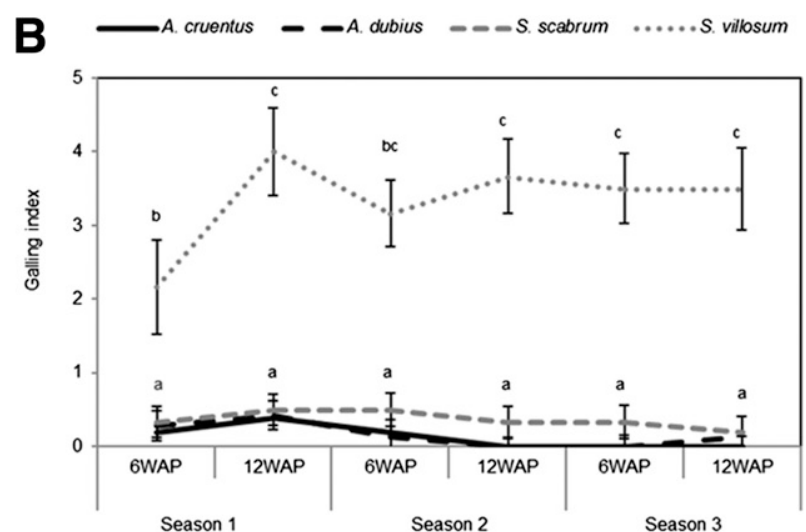

Time (weeks)

Fig. 4. Impact of African indigenous vegetables (AIV) cultivation on population dynamics of root-knot nematodes (RKN) and subsequent nematode management in tomato. (A) RKN population densities under AIV cultivation for three successive seasons; (B) Root galling on AIV crops; (C) Galling index and the number of flowers on Solanum lycopersicum at 6 weeks after planting following three successive (3S) cultivations of AIV. Values of the bars with different letters are significantly different at $P \leq 0.05$ using Tukey posthoc multiple comparisons test. Error bars represent standard deviation of mean. In section C, dark bars represent primary axis and light bars represent secondary axis. A - Amaranthus, S Solanum. 
trial was conducted at a site that had natural soil infestation of $G$. rostochiensis, G. pallida, and an associated Globodera sp. The same site also had a natural infestation of RKN. At the beginning of the experiment (season 1), there were no significant differences in PCN population densities among the different AIV crops. By the end of season 1, population densities of PCN (measured as viable eggs/cyst) were significantly lower on $S$. scabrum and $S$. villosum compared with $A$. dubius and A. cruentus or fallow (Fig. 5A). In seasons 2 and 3, these dynamics continued. After three successive seasons of cultivation of AIV, a PCN-susceptible $S$. tuberosum cv. Shangi had different responses in wilting incidences, number of PCN females, and number of flowers at 6 weeks after planting. The incidence of wilting on $S$. tuberosum was significantly reduced when planted after $S$. scabrum and S. villosum (Fig. 5B), but wilted and stunted S. tuberosum plants were observed under fallow and A. dubius. The number of PCN females was lower in $S$. scabrum and $S$. villosum compared with $A$. dubius and fallow (Fig. 5C). The effect of AIV on RKN-PCN coinfection also varied. Potato plants with both root galls and PCN females were observed. RKN-PCN coinfection on S. tuberosum was significantly reduced when planted after $S$. scabrum, S. villosum, and $A$. dubius, and the number of flowers was higher in $S$. tuberosum planted after S. scabrum (Fig. 5D).

\section{Discussion}

Parasitism of crops by RKN and PCN is a major constraint for food production. In Africa, smallholder cropping systems are complicated and often characterized by simultaneous cultivation of crop species that support development of RKN and PCN. Hence, the current farming system increases the economic impact of these nematodes.
AIV including African nightshade ( $S$. scabrum and $S$. villosum) and African spinach (A. dubius and A. cruentus) are neglected and underutilized crops, but have been a part of farming practices and nutrition in traditional societies in Africa. However, there is a lack of information on their host status to RKN and PCN, and so far no study has focused on the impact of these crops on RKN and PCN dynamics. Here, we demonstrate that reintroduction of African nightshade and African spinach into cropping systems can be used to reduce RKN and PCN populations and yield effects on following susceptible crop species.

Implementation of an effective management strategy to control plant-parasitic nematodes requires accurate nematode species identification and their respective host plants (Taylor and Sasser 1978). Thus, in this study, we first characterized the different RKN and PCN infecting S. scabrum, S. villosum, S. lycopersicum, S. tuberosum, A. dubius, and A. cruentus. We employed both morphological and molecular approaches to identify the RKN and PCN species. Current morphological identification procedures were able to differentiate some, but not all, of the RKN. Despite morphological identification failing to give a clear resolution to separate tropical RKN species such as $M$. javanica, $M$. arenaria, and $M$. incognita, the other $\mathrm{RKN}, M$. hapla, M. enterolobii, and an associated Meloidogyne sp. were clearly separated from each other by using perineal patterns (Eisenback et al. 1980). The widely used barcode gene COI reliably differentiated M. hapla, M. enterolobii, and Meloidogyne sp. from the other tropical RKN. The recently identified NAD5 gene fragment DNA marker (Janssen et al. 2016) allowed a reliable identification of the most common tropical RKN $M$. javanica, M. arenaria, and $M$. incognita. The phylogenetic position of an associated Meloidogyne
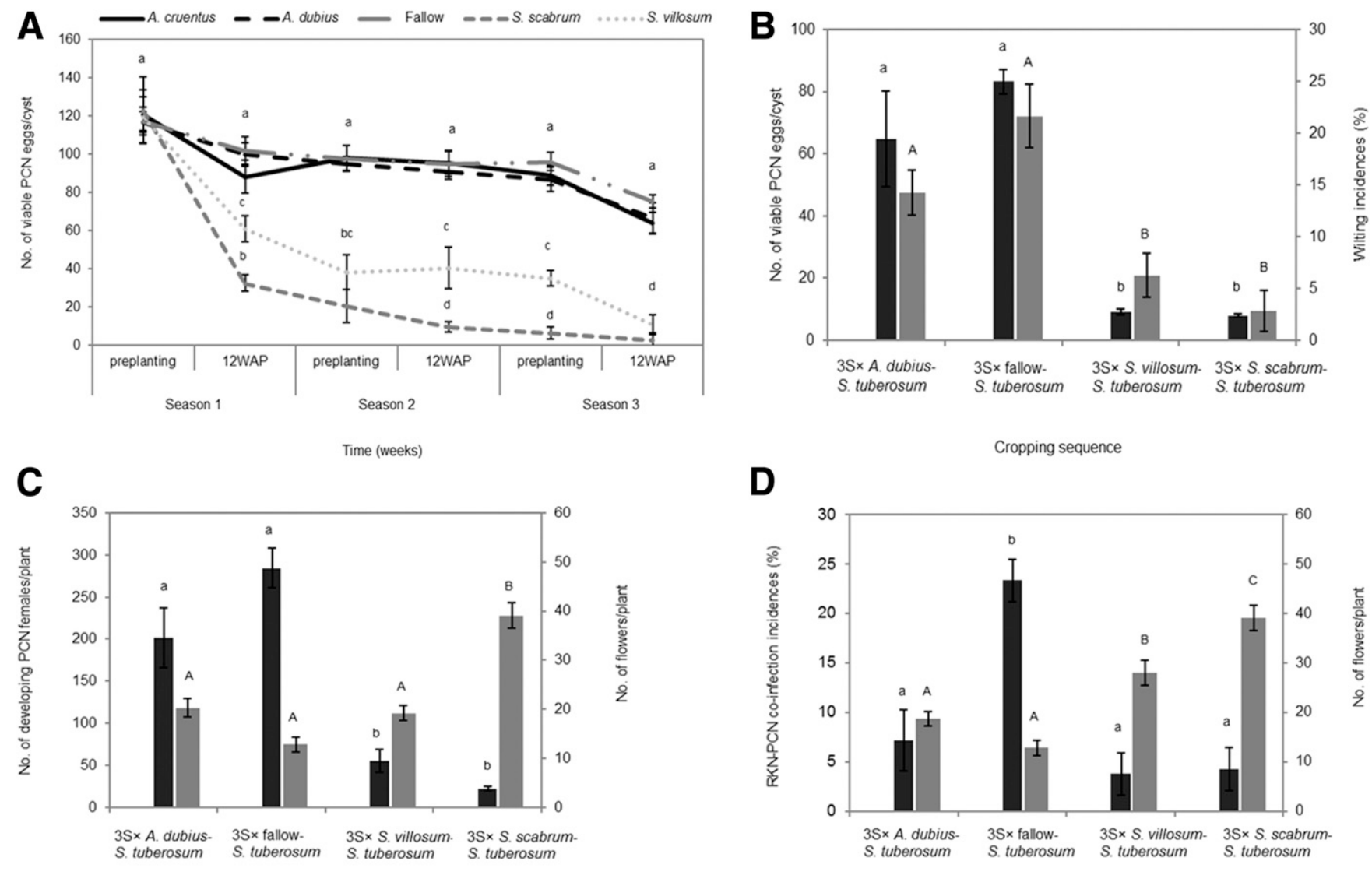

Cropping sequence

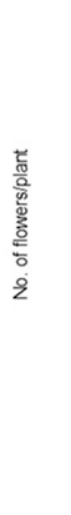

Fig. 5. Impact of African indigenous vegetables (AIV) cultivation on population dynamics of potato cyst nematodes (PCN) and subsequent nematode management in potato. (A) PCN population densities under AIV cultivation for three successive seasons; (B) PCN population densities and wilting incidences on Solanum tuberosum at 6 weeks after planting following three successive (3S) cultivations of AIV; (C) Number of developed PCN females and the number of flowers on S. tuberosum at 6 weeks after planting following three successive (3S) cultivations of AIV; (D). Coinfection incidences and the number of flowers on S. tuberosum at 6 weeks after planting following three successive (3S) cultivations of AIV. Values of the bars with different letters are significantly different at $P \leq 0.05$ using Tukey posthoc multiple comparisons test. Error bars represent standard deviation of mean. In section $B, C$, and $D$, dark bars represent primary axis and light bars represent secondary axis. A - Amaranthus, S - Solanum. 
sp. indicates a closer relationship with $M$. africana, which was previously reported on coffee (Janssen et al. 2017). Furthermore, COI gene sequence identified G. rostochiensis and G. pallida and reliably differentiates the associated Globodera sp. from the other PCN. The presence of G. rostochiensis and G. pallida parasitizing S. tuberosum was recently reported in Kenya (Mburu et al. 2018; Mwangi et al. 2015). The phylogenetic position of the associated Globodera sp. indicates a closer relationship with $G$. ellingtonae, which was previously reported on potato (Handoo et al. 2012). Remarkably, most RKN and PCN lineages identified in the current study have a global distribution favoring the hypothesis that spread was aided by humans through agriculture (Castagnone-Sereno et al. 2013).

We detected nematode species such as M. hapla, G. rostochiensis, and G. pallida, which are usually found in temperate climates, in a moderate tropical climate. It shows that these nematode species have the ability to successfully compete with tropical species. It underlines that temperate nematode species have to be considered as pathogens in tropical and subtropical management systems. Temperate RKN such as $M$. hapla have already been reported in subtropical conditions (Chitambo et al. 2018; Meressa et al. 2014), indicating the ability of these nematodes to adapt their temperature or climate preferences. This underpins the need for a proper nematode diagnosis. It also highlights that crops have to be resistant against several RKN and PCN species for nematode management under the current situation in many parts of Africa.

RKN were mainly associated with $S$. villosum, $S$. lycopersicum, and $S$. tuberosum, indicating that RKN are capable of causing damage on these crop species. In fact, they had been previously reported as good hosts for RKN (Nchore et al. 2013; Onkendi et al. 2014; Sikora and Fernandez 2005). By contrast, A. dubius and A. cruentus showed resistance to the studied RKN species, and only $M$. incognita were able to induce very few galls on these species. In the literature, the host status of Amaranthus spp. to RKN is not clear. Previously, it was shown that several Amaranthus species were resistant to RKN (Babatola and Awoderu 1986; Reddy et al. 1980). Later, Ferris et al. (1993) found that A. caudatus, A. hypochondriacus, and A. cruentus were nonhosts to $M$. chitwoodi, and $A$. retroflexus was rated as a poor host for $M$. chitwoodi. In contrast, a recent study indicated that $A$. tricolor supports $M$. incognita reproduction (Vaingankar et al. 2018). This suggests that the genus Amaranthus is highly diverse and is composed of many species and possibly varieties that vary in response to Meloidogyne infection. In principle, there are three types of plant responses to Meloidogyne infection: (i) susceptible - indicated by nematode development and plant damage; (ii) resistant causing low root galling in A. dubius and A. cruentus resulting in low nematode reproduction; and (iii) tolerant - showing low reduction of root and shoot traits but strongly supporting nematode development. The latter was described in a recent study which demonstrated that $A$. tricolor genotype IC-0598184 performed well after infection by $M$ incognita (Vaingankar et al. 2018). The fact that $A$. dubius and A cruentus were resistant to RKN identified in this study make them ideal candidates for RKN management.

PCN identified in this study were only associated with $S$. lycopersicum and S. tuberosum, but not S. scabrum and S. villosum, indicating resistance in these crops. S. scabrum and $S$. villosum belongs to the Solanaceae family, and Scholte (2000) reported the ability of non-tuber-bearing Solanaceae plants to stimulate PCN hatching. In contrast, non-Solanaceae plants such as A. dubius and A. cruentus do not have an effect on PCN hatching. Thus, after successive cultivation of African nightshade, the number of developing PCN observed on S. tuberosum was reduced. Dandurand et al. (2013) used a resistant trap crop, Solanum sisymbriifolium to control PCN, and this approach decreased PCN cyst infestation in the soil by more than $90 \%$. Related nightshade belonging to the non-tuber-bearing species in the Solanum genus have been demonstrated to stimulate PCN egg hatch and to prevent further development of PCN. We found a similar effect of the analyzed nightshades in our study.

Simultaneous occurrence of two or more different nematode species renders host resistance deployed against one species ineffective, because another species is not affected by the resistance response. It is known that tomato cultivars carrying $M i-1.2$ gene introgressed from Solanum peruvianum are resistant to $M$. incognita, $M$. javanica, and $M$. aranaria, but not $M$. enterolobii (Kiewnick et al. 2009). In Africa, multiple species of RKN infections have been reported (Chitambo et al. 2018; Kolombia et al. 2017), indicating that multiple nematode infections are ubiquitous in Africa, but too often ignored. Our results indicate that $A$. dubius and A. cruentus are resistant to the studied RKN species including $M$. enterolobii. This species has been reported to overcome resistance of most cultivated crops carrying resistance genes against other RKN, including resistant cotton, sweet potato, tomatoes ( $M i-1$ gene), soybean (Mirl gene), potato ( $M h$ gene), sweet pepper (Tabasco gene), bell pepper ( $N$ gene), and cowpea ( $R k$ gene) (Berthou et al. 2003; Brito et al. 2007; CastagnoneSereno 2012; Cetintas et al. 2008; Yang and Eisenback 1983).

Our studies indicate that AIV resistant to RKN and/or PCN are ideal cover crops for management of both of the groups of nematodes or can be used as rotational crops, relay crops etc. as well. Integrating these crops in the smallholder cropping system as cover crops, rotational crops, or relay crops has several advantages including nematode control and dietary diversification. Elsewhere, cover crops are used in various production systems to provide many benefits such as pest and disease management, addition of organic matter to soil, and increased productivity of cash crops. For example, the use of cover crops in the Brassicaceae family such as oilseed radish, white mustard, and winter rapeseed decreased sugar beet cyst nematode population densities (Lelivelt and Hoogendoorn 1993; Wen et al. 2017).

In summary, we have shown that accurate diagnosis of RKN and PCN will help provide proper implementation of an effective management decision. We identified A. dubius and S. scabrum with the ability to suppress RKN species identified in this study, whereas $S$. scabrum and $S$. villosum suppressed the identified PCN species. $S$. scabrum suppressed both RKN and PCN identified in this study. According to our results, these crop species can be used to manage RKN and PCN. We recommend that growers intending to simultaneously control PCN and RKN should use $S$. scabrum. Although $S$. villosum was able to suppress PCN, it is highly susceptible to RKN and should not be used where RKN are detected. This finding is a major relief to the resource constrained smallholder farmers who are overburdened by plant-parasitic nematodes, pests, and diseases as well as nutritional challenges. The reintroduction of AIV species into the existing cropping systems may be a way of promoting agro-biodiversity to improve resilience to plant-parasitic nematodes, pests, and diseases as well as dietary diversification in Africa. Therefore, this approach can be used as a simple management strategy for RKN and PCN in an environmentally friendly, effective, and productive way.

\section{Acknowledgments}

We thank Moses Nyongesa and the KALRO staff for maintaining the field sites; Gisela Sichtermann and Kelvin Gitau for nematode maintenance; and Sebastian Eves-van den Akker of University of Cambridge for providing mtDNA sequence of G. rostochiensis, G. pallida, and G. ellingtonae used for comparison in this study.

\section{Literature Cited}

Altschul, S. F., Gish, W., Miller, W., Myers, E. W., and Lipman, D. J. 1990. Basic local alignment search tool. J. Mol. Biol. 215:403-410.

Anonymous. 2017. PM 7/40 Globodera rostochiensis and Globodera pallida. EPPO Bull. 47:174-197.

Babatola, J. O., and Awoderu, J. B. 1986. Screening of Amaranthus germ plasm against root-knot nematode, Meloidogyne incognita. Ann. Appl. Biol. 108: 140-141.

Bartlem, D. G., Jones, M. G., and Hammes, U. Z. 2013. Vascularization and nutrient delivery at root-knot nematode feeding sites in host roots. J. Exp. Bot. 65:1789-1798

Bélair, G., Dauphinais, N., and Mimee, B. 2016. Evaluation of cultural methods for the management of the golden nematode (Globodera rostochiensis) in Quebec, Canada. Can. J. Plant Pathol. 38:209-217.

Berthou, F., Kouassi, A., Bossis, M., Dantec, J. P., Eddaoudi, M., Ferji, Z., Pellé, R., Taghzouti, M., Ellisséche, D., and Mugniéry, D. 2003. Enhancing the resistance of the potato to southern root-knot nematodes by using Solanum sparsipilum germplasm. Euphytica 132:57-65. 
Boydston, R. A., Mojtahedi, H., Bates, C., Zemetra, R., and Brown, C. R. 2010. Weed hosts of Globodera pallida from Idaho. Plant Dis. 94:918.

Brito, J. A., Stanley, J. D., Kaur, R., Cetintas, R., Di Vito, M., Thies, J. A., and Dickson, D. W. 2007. Effects of the Mi-1, N, and Tabasco genes on infection and reproduction of Meloidogyne mayaguensis on tomato and pepper genotypes. J. Nematol. 39:327-330.

Castagnone-Sereno, P. 2012. Meloidogyne enterolobii (=M. mayaguensis): Profile of an emerging, highly pathogenic, root-knot nematode species. Nematology 14:133-138.

Castagnone-Sereno, P., Danchin, E. G. J., Perfus-Barbeoch, L., and Abad, P. 2013. Diversity and evolution of root-knot nematodes, genus Meloidogyne: new insights from the genomic era. Annu. Rev. Phytopathol. 51:203-220.

Cernansky, R. 2015. The rise of Africa's super vegetables. NATNEWS 522:146.

Cetintas, R., Brito, J. A., and Dickson, D. W. 2008. Virulence of four Florida isolates of Meloidogyne mayaguensis to selected soybean genotypes. Nematropica 38:127-136.

Chitambo, O., Haukeland, S., Fiaboe, K. K. M., and Grundler, F. M. 2018. First report of Meloidogyne hapla and Meloidogyne javanica co-infection on Parthenium hysterophorus in Kenya. Plant Dis. 103:162. https://apsjournals. apsnet.org/doi/abs/10.1094/PDIS-06-18-0964-PDN.

Chitambo, O., Haukeland, S., Fiaboe, K. K. M., Kariuki, G. M., and Grundler, F. M. W. 2016. First report of the root-knot nematode Meloidogyne enterolobii parasitizing African nightshades in Kenya. Plant Dis. 100:1954.

Collange, B., Navarrete, M., Peyre, G., Mateille, T., and Tchamitchian, M. 2011 Root-knot nematode (Meloidogyne) management in vegetable crop production: The challenge of an agronomic system analysis. Crop Prot. 30:1251-1262.

Coyne, D. L., Cortada, L., Dalzell, J. J., Claudius-Cole, A. O., Haukeland, S., Luambano, N., and Talwana, H. 2018. Plant-parasitic nematodes and food security in sub-Saharan Africa. Annu. Rev. Phytopathol. 56:381-403.

Cray, J. A., Connor, M. C., Stevenson, A., Houghton, J. D., Rangel, D. E., Cooke, L. R., and Hallsworth, J. E. 2016. Biocontrol agents promote growth of potato pathogens, depending on environmental conditions. Microb. Biotechnol. 9: 330-354.

Dandurand, L. M., Brown, C. R., Knudsen, G. R., Filip, C. J., and Gajjar, P. 2013. Potential of Solanum sisymbriifolium as a trap crop for the control of the pale cyst nematode Globodera pallida. J. Nematol. 45:286.

Derycke, S., Vanaverbeke, J., Rigaux, A., Backeljau, T., and Moens, T. 2010. Exploring the use of cytochrome oxidase c subunit 1 (COI) for DNA barcoding of free-living marine nematodes. PLoS One 5:e13716.

Dinssa, F. F., Hanson, P., Dubois, T., Tenkouano, A., Stoilova, T., Hughes, J., and Keating, J. D. H. 2016. AVRDC-The World Vegetable Center's womenoriented improvement and development strategy for traditional African vegetables in sub-Saharan Africa. Eur. J. Hortic. Sci. 81:91-105.

Djian-Caporalino, C., Molinari, S., Palloix, A., Ciancio, A., Fazari, A., Marteu, N., Ris, N., and Castagnone-Sereno, P. 2011. The reproductive potential of the root-knot nematode Meloidogyne incognita is affected by selection for virulence against major resistance genes from tomato and pepper. Eur. J. Plant Pathol. 131:431-440.

Dropkin, V. 1972. Pathology of Meloidogyne-Galling, giant cell formation, effects on host physiology. EPPO Bull. 2:23-32.

Eisenback, J. D., Hirschmann, H., and Triantaphyllou, A. C. 1980. Morphological comparison of Meloidogyne female head structures, perineal patterns, and stylets. J. Nematol. 12:300-313.

Ferris, H., Carlson, H. L., Viglierchio, D. R., Westerdahl, B. B., Wu, F. W., Anderson, C. E., Juurma, A., and Kirby, D. W. 1993. Host status of selected crops to Meloidogyne chitwoodi. J. Nematol. 25:849-857.

Fournet, S., Eoche-Bosy, D., Kerlan, M. C., Grenier, E., and Montarry, J. 2018. Phenotypic and genomic modifications associated with Globodera pallida adaptation to potato resistances. Potato Res. 61:65-71.

Gruber, K. 2017. Agrobiodiversity: The living library. Nature 544:S8-S10.

Handoo, Z. A., Carta, L. K., Skantar, A. M., and Chitwood, D. J. 2012. Description of Globodera ellingtonae n. sp. (Nematoda: Heteroderidae) from Oregon. J. Nematol. 44:40-57.

Huang, C. S. 1985. Formation, anatomy and physiology of giant cells induced by root-knot nematodes. Pages 155-164 in: An Advanced Treatise on Meloidogyne. J. N. Sasser and C. C. Carter, eds. Vol. 1. North Carolina State University Graphics, Raleigh, NC.

Hussey, R. S., and Grundler, F. M. W. 1998. Nematode parasitism of plants. Pages 213-243 in: Physiology and Biochemistry of Free Living and Plant Parasitic Nematodes. R. N. Perry and D. J. Wright, eds. CAB International, Oxon, UK.

Janssen, T., Karssen, G., Topalović, O., Coyne, D., and Bert, W. 2017. Integrative taxonomy of root-knot nematodes reveals multiple independent origins of mitotic parthenogenesis. PLoS One 12:e0172190.

Janssen, T., Karssen, G., Verhaeven, M., Coyne, D., and Bert, W. 2016. Mitochondrial coding genome analysis of tropical root-knot nematodes (Meloidogyne) supports haplotype based diagnostics and reveals evidence of recent reticulate evolution. Sci. Rep. 6:22591.

Jepson, S. B. 1987. Identification of Root-Knot Nematodes (Meloidogyne species). CAB International, Wallingford, UK

Jones, M. 1981. Host cell responses to endoparasitic nematode attack: Structure and function of giant cells and syncytia. Ann. Appl. Biol. 97:353-372.

Kiewnick, S., Desimoz, M., and Franck, L. 2009. Effects of the Mi-1 and the $N$ root-knot nematode-resistance gene on infection and reproduction of Meloidogyne enterolobii on tomato and pepper cultivars. J. Nematol. 41: 134-139.

Kokalis-Burelle, N., and Rosskopf, E. N. 2012. Susceptibility of several common subtropical weeds to Meloidogyne arenaria, M. incognita, and $M$. javanica. J. Nematol. 44:142-147.

Kolombia, Y. A., Karssen, G., Viaene, N., Kumar, P. L., de Sutter, N., Joos, L., Coyne, D. L., and Bert, W. 2017. Diversity of root-knot nematodes associated with tubers of yam (Dioscorea spp.) established using isozyme analysis and mitochondrial DNA-based identification. J. Nematol. 49: $177-188$

Kottek, M., Grieser, J., Beck, C., Rudolf, B., and Rubel, F. 2006. World map of the Köppen-Geiger climate classification updated. Meteorol. Z. (Berl.) 15:259-263.

Lelivelt, C. L. C., and Hoogendoorn, J. 1993. The development of juveniles of Heterodera schachtii in roots of resistant and susceptible genotypes of Sinapis alba, Brassica napus, Raphanus sativus and hybrids. Neth. J. Plant Pathol. 99:13-22.

Mburu, H., Cortada, L., Mwangi, G., Gitau, K., Kiriga, A., Kinyua, Z. M., Ngundo, G., Ronno, W., Coyne, D. L., Holgado, R., and Haukeland, S. 2018. First report of potato cyst nematode Globodera pallida (Stone, 1973) infecting potato (Solanum tuberosum L.) in Kenya. Plant Dis. 102:1671.

Meressa, B. H., Heuer, H., Dehne, H. W., and Hallmann, J. 2014. First report of the root-knot nematode Meloidogyne hapla parasitizing roses in Ethiopia. Plant Dis. 98:1286.

Moyo, S. M., Mavumengwana, V., and Kayitesi, E. 2017. Effects of cooking and drying on phenolic compounds and antioxidant activity of African green leafy vegetables. Food Rev. Int. 34:1-17.

Mwangi, J. M., Kariuki, G. M., Waceke, J. W., and Grundler, F. M. 2015. First report of Globodera rostochiensis infesting potatoes in Kenya. New Dis. Rep. 31:18

Mwaura, P., Niere, B., and Vidal, S. 2017. Application of an entomopathogenic fungus (Beauveria bassiana) increases potato nematodes reproduction and potato tubers damage caused by Ditylenchus destructor and D. dipsaci. Biol. Control 115:23-29.

Nchore, S. B., Waceke, J. W., and Kariuki, G. M. 2013. Response of African leafy vegetables to Meloidogyne spp. in Kenya. J. Todays Biol. Sci. Res. Rev. 2:1-12.

Neugart, S., Baldermann, S., Ngwene, B., Wesonga, J., and Schreiner, M. 2017 Indigenous leafy vegetables of Eastern Africa-a source of extraordinary secondary plant metabolites. Food Res. Int. 100:411-422.

Nicol, J. M., Turner, S. J., Coyne, D., Den Nijs, L., Hockland, S., and Maafi, Z. T. 2011. Current nematode threats to world agriculture. Pages 21-43 in: Genomics and Molecular Genetics of Plant-Nematode Interactions. J. Jones, G. Gheysen, and C. Fenoll, eds. Springer, Dordrecht, The Netherlands.

Onkendi, E. M., Kariuki, G. M., Marais, M., and Moleleki, L. N. 2014. The threat of root-knot nematodes (Meloidogyne spp.) in Africa: A review. Plant Pathol. 63:727-737.

Perry, R. 1989. Dormancy and hatching of nematode eggs. Parasitol. Today 5: 377-383.

Perry, R. N., and Clarke, A. J. 1977. Hatching of cyst-nematodes. Nematologica 23:350-368.

Pickup, J. 2016. Management of the potato cyst nematodes Globodera pallida and G. rostochiensis. J. Nematol. 48:362.

Reddy, P. P., Singh, D. B., and Rajendran, R. 1980. Reaction to some species and varieties of Amaranthus to Meloidogyne incognita. Indian J. Nematol. 10:100-102.

Riley, M. B., Williamson, M. R., and Maloy, O. 2002. Plant disease diagnosis Plant Health Instr.

Rodríguez-Kábana, R., King, P. S., Robertson, D. G., and Weaver, C. F. 1988 Potential of crops uncommon to Alabama for management of root-knot and soybean cyst nematodes. Ann. Appl. Nematol. 2:116-120.

Rott, M., Lawrence, T., and Belton, M. 2011. Nightshade hosts for Canadian isolates of Globodera rostochiensis pathotype Ro1. Can. J. Plant Pathol. 33: 410-415.

Scholte, K. 2000. Screening of non-tuber bearing Solanaceae for resistance to and induction of juvenile hatch of potato cyst nematodes and their potential for trap cropping. Ann. Appl. Biol. 136:239-246.

Sijmons, P. C., Grundler, F. M., Mende, N., Burrows, P. R., and Wyss, U. 1991. Arabidopsis thaliana as a new model host for plant-parasitic nematodes. Plant J. 1:245-254.

Sikora, R. A., and Fernandez, E. 2005. Nematode parasites of vegetables. Pages 319-392 in: Plant-Parasitic Nematodes in Subtropical and Tropical Agriculture, 2nd ed. M. Luc, R. A. Sikora, and J. Bridge, eds. CABI Publishing, Wallingford, UK

Tamura, K., Stecher, G., Peterson, D., Filipski, A., and Kumar, S. 2013. MEGA6: Molecular evolutionary genetics analysis version 6.0. Mol. Biol. Evol. 30: 2725-2729.

Taylor, A. L., and Sasser, J. N. 1978. Biology, identification, and control of root-knot nematodes (Meloidogyne species). A cooperative publication of the Department of Plant Pathology, North Carolina State University, and the U.S. Agency for International Development. North Carolina State University Graphics, Raleigh, NC.

Trudgill, D. L., Phillips, M. S., and Elliott, M. J. 2014. Dynamics and management of the white potato cyst nematode Globodera pallida in commercial potato crops. Ann. Appl. Biol. 164:18-34. 
Ukam, N. U., Mgbekem, M. A., Edide, R., and Obizoba, I. C. 2016. Nutrient and phytochemical composition of five wild green leafy vegetables consumed in Erie-Biase local government area of Cross River State. Food Nutr. (Roma) 7: 817-823.

Vaingankar, J. D., Maruthadurai, R., Sellaperumal, C., Dhargalkar, S. D., Harihar, S., and Arunachalam, V. 2018. Tapping the potential of vegetable Amaranth genotype to trap the root knot nematode pest. Sci. Hortic. (Amsterdam) 230:18-24.

Ward, E., Kerry, B. R., Manzanilla-López, R. H., Mutua, G., Devonshire, J., Kimenju, J., and Hirsch, P. R. 2012. The Pochonia chlamydosporia serine protease gene vcp1 is subject to regulation by carbon, nitrogen and $\mathrm{pH}$ : Implications for nematode biocontrol. PLoS One 7:e35657.
Wen, L., Lee-Marzano, S., Ortiz-Ribbing, L. M., Gruver, J., Hartman, G. L. and Eastburn, D. M. 2017. Suppression of soilborne diseases of soybean with cover crops. Plant Dis. 101:1918-1928.

Wesemael, W. M., Viaene, N., and Moens, M. 2011. Root-knot nematodes (Meloidogyne spp.) in Europe. Nematol. 13:3-16.

Yang, B., and Eisenback, J. D. 1983. Meloidogyne enterolobii n. sp. (Meloidogynidae), a root-knot nematode parasitizing pacara earpod tree in China. J. Nematol. 15:381-388.

Zasada, I. A., Halbrendt, J. M., Kokalis-Burelle, N., LaMondia, J., McKenry, M. V., and Noling, J. W. 2010. Managing nematodes without methyl bromide. Annu. Rev. Phytopathol. 48:311-328. 